\title{
A new model of the evaluation of the quality of students for parallel application based on multivariate analysis
}

\author{
Huasheng Chen \\ Admission Office of Northwestern Polytechnical \\ University \\ Xi'an, China \\ xiaochenh@nwpu.edu.cn
}

\author{
Jinming Liu \\ School of Science of Northwestern Polytechnical \\ University \\ Xi'an, China
}

\author{
Youmiao Qu, Haobing Shi \\ School of Computer Science and Technology of Northwestern Polytechnical University \\ Xi'an, China
}

\begin{abstract}
Student quality evaluation is important for admissions and exploring a suitable model is an indispensable part. In recent years, a new voluntary approach calls "parallel application" brings reform in entrance examination in China. However, it leads to a narrower admission score range, which challenges the evaluation work. In this paper, we choose a key university in northwest China as a specific example. Pay attention to both the quality of student source and the work target. We use factor analysis and cluster analysis of multivariate statistical analysis method to analyze the data collected from 16 provinces. Then according to the factor score of each sample point, we sort and classify the quality of students in different provinces .Compared with the traditional evaluation model, the new model adds two parts of index, the basic index and the extended index, as the basis to handle the parallel evaluation challenge. The result shows that the model is fit for the evaluation of the parallel application approach.
\end{abstract}

Keywords---Student quality evaluation; Parallel application; Multivariate analysis; Undergraduate admissions

\section{INTRODUCTION}

The quality of students, which would determine the university talents training, has becoming an most important basis of sustainable development at university. College Entrance Examination System, which is a main way of selecting the genius, is in the process of reform. Admissions office must set up enrollment system in correspondence with the new situation. To ensure the quality of students, it is urgent to develop scientific methods and theories for decision making.

Student quality evaluation is to establish a set suitable Quality Evaluation System for university. According to the objectives and standards, evaluation of the quality of students is also the process of judging the quantity and the quality of students. Research and discussion on the evaluation model is the research focus of in every college admissions offices and higher education management. Juan Xiong [1] applies the theory of educational evaluation to establish a system of evaluation of the quality of students, and considers that the current college entrance examination system should not take all factors, but should grasp the key factors of evaluation and analysis. Tongshan Chang [2] describes the California American University Admissions comprehensive assessment method, which takes multidimensional evaluation standard to ensure to enroll students with all-round development and genuine talent, and adds to the whole development of university in the long run, which provides a reference for us in the aspects of evaluation of the quality. Yusheng Tang, etc. [3] use fuzzy mathematical tool for the analysis of the quality of students. The report [4] makes detailed analysis of the system of evaluation of the quality of students and Calculation method. At present the findings mainly concentrated on the superiority-inferiority in the traditional model of evaluation.

In recent years, the parallel application becomes an important measure of entrance examination reform and the admission scores of this new enrollment mode are flat. The analysis of the quality of students, mainly consults the ranking of the examinees in the college entrance examination. Comparing with the traditional evaluation model and method, admissions offices urgently need to study a new evaluation model from the following two aspects. First, the evaluation result. In the traditional College Entrance Voluntary Table, as the test takers can only fill the first choice, they may have the trend to choose the college carefully based on the college entrance examination results. Carrying out parallel application, students are able to fill a plurality of first choice at same time. They fill their application based on university ranking, which makes the admission results present that it is a high correlation between the ranking in the college entrance examination and university ranking, and it leads to the score section of college admission is narrow, that is to say, the distinction of the scores is small, therefore, it increases the difficulty in evaluating student quality. Second, the traditional evaluation model is only attention to the insufficient of student quality, but the purpose of evaluation should also include the development of evaluation, which provides the objective index to improve the quality of 
students, and admissions office can also achieve their objectives by adjusting evaluation result.

In this paper, we take the admissions of a key university in northwest China as an example to design a new evaluation index system for parallel application. The new evaluation aims at the defects of traditional evaluation model and it contains two parts, basic index and extended index. Basic index brings about judging evaluation of the quality of students, and extended index brings about directing to achieve developmental evaluation. The model uses Relative Evaluation [1] Method, grading 16 provinces of the quality of students by multivariate analysis method so that it can provide theoretical guidance for enrollment.

\section{EVALUATING INDEX FOR THE STUDENTS OF PARALLEL APPLICATION}

According to the recent enrolment work experience of those provinces which carries out parallel application, admissions office deeply knows that the evaluation should not only meets the superiority-inferiority of the evaluation of the quality of students, which seems better, but also makes the evaluation work benefit to the development of enrollment, which is used to guide the significance for enrollment. In this paper, the indexes is divided into basic indexes and extended index (see Table I ). Basic index implement the evaluation of the quality of students on parallel application, and extended index which base on the superiority-inferiority of evaluation, inspecting the work when it carries out on the impact of the student quality.

\section{A. Index Design}

Main points in the basic index:

(a) Evaluation index that reflects the importance of traditional evaluation model scores, but also meets the characteristics of the evaluation of the quality of students for parallel application;

(b) Because the provinces of enrollment are different, the index needs to reflect the imbalance of students in different provinces.

The extended index is on the basis of the basic index, so mainly considers points as follows:

a) Basing on the work practice design index, setting goals according to the work target and the evaluation direction;

b) The introduced index is able to evaluate the results of basic index, which can guide the work.

TABLE I. TABLE1 EVALUATION OF STUDENTS OF PARALLEL APPLICATION INDEX SYSTEM

\begin{tabular}{|c|c|c|c|}
\hline Type & Name & Definition / Formula & Function and meaning \\
\hline \multirow{5}{*}{ Basic Index } & $\begin{array}{l}\text { The number of } \\
\text { enrollees }\left(\mathrm{X}_{1}\right)\end{array}$ & $\begin{array}{l}\text { The number of science student } \\
\text { admitted }\end{array}$ & $\begin{array}{c}\text { Reflected on the size of enrollment scale of the } \\
\text { province }\end{array}$ \\
\hline & $\begin{array}{l}\text { The difference } \\
\text { between the } \\
\text { average and the } \\
\text { focus on line }\left(\mathrm{X}_{2}\right)\end{array}$ & $\begin{array}{l}\text { The difference between the average of science student } \\
\text { admitted and the required score in the province. }\end{array}$ & $\begin{array}{l}\text { Reflected on dispersion of the overall grades and } \\
\text { the required score }\end{array}$ \\
\hline & $\begin{array}{l}\text { The percent of the } \\
\text { highest score }\left(\mathrm{X}_{3}\right)\end{array}$ & $\begin{array}{c}\text { The ranking of the highest score of science student } \\
\text { admitted in province } \\
\text { / the total number of science student of the } \\
\text { focus on line in the province }\end{array}$ & $\begin{array}{l}\text { Reflected on the situation of the best ranking of } \\
\text { science student admitted }\end{array}$ \\
\hline & $\begin{array}{l}\text { the percent of the } \\
\text { average }\left(\mathrm{X}_{4}\right)\end{array}$ & $\begin{array}{l}\text { The ranking of the average of } \\
\text { science student admitted in province / } \\
\text { the total number of science student of the } \\
\text { focus on line in the province }\end{array}$ & $\begin{array}{l}\text { Reflected on the situation of the average ranking } \\
\text { of science student admitted }\end{array}$ \\
\hline & $\begin{array}{l}\text { the percent of the } \\
\text { lowest mark }\left(X_{5}\right)\end{array}$ & $\begin{array}{l}\text { The ranking of the lowest mark of } \\
\text { science student admitted in province / } \\
\text { the total number of science student of the } \\
\text { focus on line in the province }\end{array}$ & $\begin{array}{l}\text { Reflected on the relative positions between the } \\
\text { lowest level of the total number of science student } \\
\text { of the focus on line in the province }\end{array}$ \\
\hline \multirow{2}{*}{$\begin{array}{l}\text { Extended } \\
\text { Index }\end{array}$} & $\begin{array}{l}\text { the contribution of } \\
\text { the average }\left(\mathrm{X}_{6}\right)\end{array}$ & $\begin{array}{l}\text { The index value of the difference between the } \\
\text { average and the focus on line in province-the } \\
\text { expectations of the difference between the } \\
\text { average and the focus on line in all provinces }\end{array}$ & $\begin{array}{l}\text { Reflected on the difference between the } \\
\text { overall level of science student admitted in the } \\
\text { provinces and the average level of college }\end{array}$ \\
\hline & $\begin{array}{l}\text { the input of } \\
\text { enrolment } \\
\text { propaganda } \\
\qquad\left(X_{7}\right)\end{array}$ & $\begin{array}{l}\text { The sum of human resources of enrolment } \\
\text { propaganda by person*day }\end{array}$ & $\begin{array}{l}\text { Directly reflect on the attention of admissions and } \\
\text { the input of admissions .From experience, } \\
\text { enrolment propaganda has } \\
\text { a positive association with the quality of enrolment }\end{array}$ \\
\hline
\end{tabular}

\section{Multivariate ANALYSIS}

Multivariate Analysis [5][6] is widely used in statistical analysis, such as education, management, medicine and ecology. It has the advantages of comprehending the information of various indicators, such as simplifying the system, performing the method of numeric taxonomy, reflecting the level of principal component and indicating all kinds of phenomenon essences scientifically.

In diagram 2 the index system can be showed by multivariant data. Set a set of sample data that the capacity is $n$. Typical data can be expressed as: 


$$
X=\left[\begin{array}{cccc}
x_{11} & x_{12} & \ldots & x_{1 n} \\
x_{21} & x_{22} & \ldots & x_{2 n} \\
\ldots & \ldots & \ldots & \ldots \\
x_{71} & x_{72} & \ldots & x_{7 n}
\end{array}\right]
$$

This $x_{i k}$ is expressed that the $i$ sample is the observations of $\mathrm{k}$ time.

By means of Multivariate analysis, evaluating the analytical index data mainly takes the following four simple steps.

\section{A. Data Processing}

As multiple variables use different measurement unit, we need to standardize the raw data in order to unify the dimensionless;

\section{B. Factor Analysis}

Use the SPSS software for the factor analysis of the standardized data, calculating the factor scores of each sample's data and make a sequencing of factor. So computing formula for factor scores such as:

$$
F_{\mathrm{ij}}=b_{1} x_{i 1}+b_{2} x_{i 2}+\cdots b_{p} x_{i p}(i=1,2, \cdots, n, j=1,2, \cdots, m)
$$

(Among them, $F_{i j}$ is expressed the factor scores of the $i$ sample for the $j$ factor, $b_{1}, b_{2}, \mathrm{~L}, b_{p}$ are the equal of the regression coefficient, corresponds to the $j$ factor)

\section{Cluster Analysis}

Take factor scores as the input of cluster analysis. The data is divided into several categories after clustering analysis, which reflects the difference of the quality of students in the provinces at the level.

\section{Preparing a Graph}

Getting the dendrogram on the basis of the results of clustering analysis to make it easier to understand the result.

\section{EXAMPLE ANALYSIS}

The evaluating index for the students of parallel application, which is divided into basic index and extended index, are used to carry out data analysis. According to index, the enrollment data collected from a key university in northwest is showed in table II.

\begin{tabular}{|c|c|c|c|c|c|c|c|c|}
\hline No. & Provinces & $\begin{array}{l}\text { The number } \\
\text { of enrollees }\end{array}$ & $\begin{array}{l}\text { The difference } \\
\text { between the } \\
\text { average and the } \\
\text { focus on line }\end{array}$ & \begin{tabular}{|c|} 
The \\
contribution of \\
the average
\end{tabular} & $\begin{array}{c}\text { The percent of the } \\
\text { highest score }\end{array}$ & $\begin{array}{l}\text { The percent of } \\
\text { the average }\end{array}$ & $\begin{array}{c}\text { The percent of } \\
\text { the lowest mark }\end{array}$ & Propagandists \\
\hline 1 & Beijing & 43 & 89 & 8.81 & $11.3 \%$ & $41.4 \%$ & $68.8 \%$ & 12 \\
\hline 2 & Hebei & 205 & 65 & -14.57 & $1.3 \%$ & $10.5 \%$ & $13.1 \%$ & 10 \\
\hline 3 & Shanxi & 104 & 71 & -9.17 & $4.8 \%$ & $9.9 \%$ & $12.8 \%$ & 8 \\
\hline 4 & Inner Mongolia & 56 & 109 & 29.12 & $4.2 \%$ & $11.8 \%$ & $18.3 \%$ & 7 \\
\hline 5 & Jilin & 41 & 76 & -3.8 & $8.8 \%$ & $18.5 \%$ & $31.4 \%$ & 5 \\
\hline 6 & Zhejiang & 103 & 57 & -23.13 & $13.3 \%$ & $24.5 \%$ & $29.9 \%$ & 8 \\
\hline 7 & Anhui & 203 & 81 & 1.05 & $3.8 \%$ & $9.5 \%$ & $12.0 \%$ & 10 \\
\hline 8 & Shandong & 196 & 73 & -7.29 & $2.2 \%$ & $8.3 \%$ & $12.2 \%$ & 14 \\
\hline 9 & Henan & 267 & 72 & -7.85 & $2.5 \%$ & $8.3 \%$ & $10.9 \%$ & 19 \\
\hline 10 & Hubei & 138 & 45 & -34.75 & $8.0 \%$ & $27.1 \%$ & $48.0 \%$ & 8 \\
\hline 11 & Guangxi & 43 & 60 & -19.97 & $7.0 \%$ & $22.0 \%$ & $27.3 \%$ & 3 \\
\hline 12 & Chongqing & 45 & 65 & -15 & $2.0 \%$ & $17.4 \%$ & $74.7 \%$ & 4 \\
\hline 13 & Sichuan & 124 & 47 & -32.58 & $4.6 \%$ & $26.2 \%$ & $84.2 \%$ & 7 \\
\hline 14 & Guizhou & 60 & 90 & 10.46 & $7.6 \%$ & $18.9 \%$ & $20.9 \%$ & 6 \\
\hline 15 & Shaanxi & 1103 & 109 & 29 & $1.3 \%$ & $10.0 \%$ & $10.8 \%$ & 36 \\
\hline 16 & Ningxia & 42 & 81 & 0.94 & $5.7 \%$ & $16.8 \%$ & $17.8 \%$ & 4 \\
\hline
\end{tabular}

TABLE II. THE ENROLLMENT DATA OF A KEY UNIVERSITY IN NORTHWEST IN SOME PROVINCES

The model parameters are showed in table III , the assessment result can be obtained by multivariate analysis of data in table II. Figure 1 shows the result of the computations based on basic index. Table IV shows the classification result, and it can be seen that the result of Shaanxi is the best, which has an obvious gap with the other two classes, so it belongs to the first class. And the second is Hebei, Anhui, Henan, Shandong and Shanxi... The last class is Beijing and so on. The data is basically consistent with the university enrollment data. In 
summary, the analysis model for the evaluation of the quality of students meets the basic needs.

TABLE III. MULTI-EVALUATION PARAMETER SETTINGS

\begin{tabular}{|l|l|}
\hline \multicolumn{1}{|c|}{ Parameter } & \multicolumn{1}{c|}{ Settings } \\
\hline principle components selected & 3 \\
\hline rotating method & maximum deviation method \\
\hline clustering method & $\begin{array}{l}\text { Hierarchical Cluster - Between- } \\
\text { groups linkage }\end{array}$ \\
\hline the cluster number & 3 \\
\hline *Note: principal component accounts for more than 93\% of total variance
\end{tabular}

In order to consider the model about the evaluation effects of extended Index, we re-evaluated the data, and then got the classified results in figure 2 and table $V$. They are showed the result that Shaanxi is still in the first class, and the number of provinces has increased in the second class. It indicates that taking the strengthening of main work in the second class of provinces should improve the situation of admissions, but as for the second class of provinces and the third class of provinces, they can continue to maintain the status quo because increasing the input does little help to improve the overall quality of that.

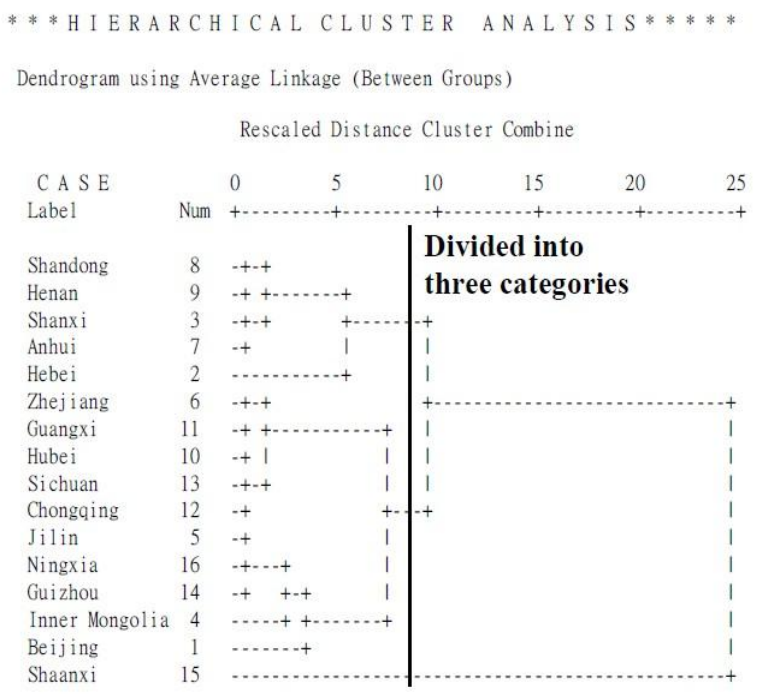

Figure 1. Dendrogram by using basic index

TABLE IV. CLASSIFICATION RESULTS BY USING BASIC INDEX

\begin{tabular}{|l|l|}
\hline \multicolumn{1}{|c|}{ Class } & \multicolumn{1}{|c|}{ Provinces } \\
\hline The first class & $\begin{array}{l}\text { Beijing, Inner Mongolia, Jilin, } \\
\text { Guizhou, Nixia, Zhejiang, Hubei, } \\
\text { Guangxi, Sichuan, Chongqing }\end{array}$ \\
\hline The second class & $\begin{array}{l}\text { Hebei, Anhui, Shandong, Henan, } \\
\text { Shanxi }\end{array}$ \\
\hline The third class & Shaanxi \\
\hline
\end{tabular}

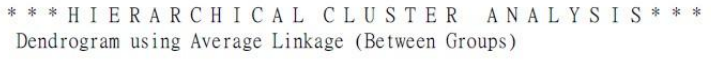

Rescaled Distance Cluster Combine

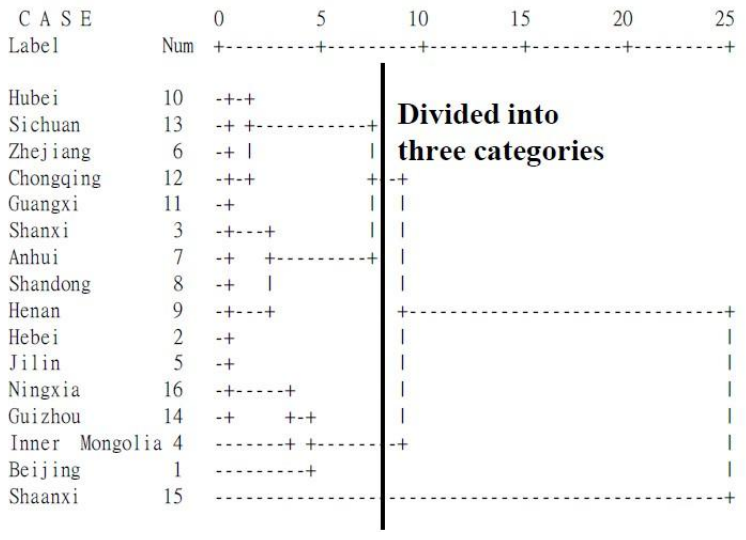

Figure 2. Dendrogram by using extended index

TABLE V. CLASSIFICATION RESULTS PLUSING EXTENDED INDEX

\begin{tabular}{|l|l|}
\hline \multicolumn{1}{|c|}{ Class } & \multicolumn{1}{|c|}{ Provinces } \\
\hline The first class & $\begin{array}{l}\text { Beijing, Inner Mongolia , Jilin, } \\
\text { Guizhou, Ningxia }\end{array}$ \\
\hline The second class & $\begin{array}{l}\text { Hebei, Anhui, Shandong, Henan, } \\
\text { Shanxi, Zhejiang, Hubei, Guangxi, } \\
\text { Sichuan, Chongqing }\end{array}$ \\
\hline The third class & Shaanxi \\
\hline
\end{tabular}

\section{CONCLUSION}

In this paper, we achieve a good result to carry out evaluation of the quality of students about parallel application which can be applied to the result in selecting advanced provinces during enrollment work. But also we should note that establishing the evaluation model is a long process, index system should be improved and amended in practice so that it can meet the development of the reform of college entrance examination system, and can be explored in the future practice in order to establish a reasonable model meeting the reality of college admissions .

\section{REFERENCES}

[1] Juan Xiong, "Evaluation Model and Empirical Study on the Quality of Admitted Students of Colleges and Universities," Master's thesis of Central South University, 2008.

[2] Tongshan Chang, An Analytical Study of the University of California Undergraduate Admissions Comprehensive Review, in Tsinghua Journal of Education, 2007, No.6, Vol.28, pp.80-88.

[3] Yusheng Tang, Huasheng Chen. "Evaluation of the quality of college enrollment based on fuzzy evaluation model," Jornal of Ningxia University (Humanities \& Social science Edition), 2008,No.4, Vol.30.

[4] "Research Outcome Report of the Study on Graduate Education Quality Evaluation,” University Academic, 2012, No.1.

[5] Huijuan Xu, Huiwen Wang, "Application of Multivariate Analysis in Studying the Graduate Schools' Scales of Universities in China," Journal of Beijing University of Aeronautics and Astronautics, 1998, Vol24,No.2. 
[6] Xiuli He, "The application of multi-variated analysis in statistics,"

Journal of Jilin Institute of Chemical Technology, 2003, (01) 72-74. 